4-18-2019

\title{
pH Dependent C-jejuni Thermal Inactivation Models And Application To Poultry Scalding
}

\author{
Zachary McCarthy \\ Cleveland State University, zjm@yorku.ca \\ Ben Smith \\ Public Health Agency of Canada \\ Aamir Fazil \\ Public Health Agency of Canada \\ Jianhong Wu \\ York University \\ Shawn D. Ryan \\ Cleveland State University, s.d.ryan@csuohio.edu \\ Follow this and additional works at: https://engagedscholarship.csuohio.edu/scimath_facpub \\ ipraxtofalal fortadditional authorsns \\ How does access to this work benefit you? Let us know! \\ Publisher's Statement \\ https://doi.org/10.1016/j.jfoodeng.2017.11.025
}

\section{Repository Citation}

McCarthy, Zachary; Smith, Ben; Fazil, Aamir; Wu, Jianhong; Ryan, Shawn D.; and Munther, Daniel, "pH Dependent C-jejuni Thermal Inactivation Models And Application To Poultry Scalding" (2019).

Mathematics Faculty Publications. 302.

https://engagedscholarship.csuohio.edu/scimath_facpub/302

This Article is brought to you for free and open access by the Mathematics and Statistics Department at EngagedScholarship@CSU. It has been accepted for inclusion in Mathematics Faculty Publications by an authorized administrator of EngagedScholarship@CSU. For more information, please contact library.es@csuohio.edu. 


\section{Authors}

Zachary McCarthy, Ben Smith, Aamir Fazil, Jianhong Wu, Shawn D. Ryan, and Daniel Munther 


\title{
$\mathrm{pH}$ dependent $C$. jejuni thermal inactivation models and application to poultry scalding
}

\author{
Zachary McCarthy ${ }^{a}{ }^{*}$, Ben Smith ${ }^{c}$, Aamir Fazil ${ }^{c}$, Jianhong $W^{b}{ }^{b}$, Shawn D. Ryan ${ }^{a}$, \\ Daniel Munther ${ }^{\text {a }}$ \\ a Department of Mathematics, Cleveland State University, Cleveland, OH, USA \\ ${ }^{\mathrm{b}}$ Laboratory for Industrial and Applied Mathematics, York University, Toronto, ON, Canada \\ ${ }^{\complement}$ Public Health Risk Sciences Division, National Microbiology Laboratory, Public Health Agency of Canada, Guelph, ON, Canada
}

\section{Introduction}

Campylobacter jejuni, a major cause of foodborne illness, continues to cause millions of cases of illness in humans (e.g. gastroenteritis) annually. An estimated $20-150$ cases are reported per 100,000 people in industrialized nations each year (Olson et al., 2008). A primary driver is consumption of undercooked poultry products (FAO/WHO, 2009). Modern studies report Campylobacter prevalence of retail poultry carcasses to be $57.7 \%$ in Canada, $58.8 \%$ in Japan, and 90\% in the United Kingdom (Suzuki and Yamamoto, 2009; Moran et al., 2009). Furthermore, an estimated 24\% and $46 \%$ of processors be will unable to pass stricter 2015 FSIS-USDA Campylobacter performance standards for raw chicken carcasses and not-ready-to-eat communicated chicken parts, respectively (US Department of Agriculture and Service, 2015).

While $C$. jejuni originates in the gastrointestinal tract of poultry, each bacterium finds its way onto the skin and feathers through external means (FAO/WHO, 2009). Birds are contaminated externally due to excreta buildup in densely populated living conditions. Contamination may not be eliminated during processing before retail sale and consumption. Of steps bringing a live chicken to retail, the slaughterhouse is a site of concern. The scalding process has been identified as a site providing opportunity for crosscontamination by the World Health Organization (FAO/WHO, 2009). In addition, cross-contamination between birds has been shown to be highly prevalent in scalding (Mulder et al., 1978).

Scalding background: Scalding is one of many stages in the poultry process. Typically, it is conducted immediately after chickens have been killed and bled out. As the first cleaning stage of poultry processing, bacteria and organic material levels are among the highest prior to scalding (FAO/WHO, 2009). Hence the opportunities for cross-contamination are abundant in this early processing stage. The two methods of scalding currently used in largescale processing plants are immersion and steam, where the former is most widely adopted and the main focus of this work. During a 
typical two minute immersion scald, birds are immersed in $50-60^{\circ} \mathrm{C}$ aerated (scald) water to prepare birds for defeathering, wash off dirt and organic material, and reduce bacteria levels. Many foodborne pathogens associated with poultry, including C. jejumi, are heat sensitive and are inactivated thermally in the scalding temperature range (FAO/WHO, 2009).

Chemical additives in scalding: It is popular among poultry processors to utilize chemical additives and antimicrobials in scald water to enhance the killing of bacteria. By altering water chemistry and $\mathrm{pH}$, the rate of bacterial inactivation also changes. However, conflicting experimental results on the efficacy of chemical additives indicate a more detailed understanding of the bacterial inactivation process may prove useful in pathogen control. We invite the reader to see our review of experiments using additives including bacteria counts and prevalence in AppendixA (Lillard et al., 1987; Okrend et al.; Humphrey and Lanning, 1987; Berrang et al., 2011).

In order to gain predictive insight on how scald water temperature and $\mathrm{pH}$ affect the inactivation of $C$. jejuni, we construct and utilize mathematical models. The power here is that, along with industrial scale data, such models can test mechanistic hypotheses as well as provide quantifiable connections between processing parameters and resulting bacteria levels in both the scald water and on chicken carcasses. In light of this perspective, the paper is organized as follows: first, in Section 2, we develop an inactivation model linking $\mathrm{pH}$ and temperature to death rates of $C$. jejuni in scald water using recent experimental data. Second, in Section 3, we present a mathematical model describing inactivation and transfer of $C$. jejuni in the immersion scalding process. In Section 4, we validate our findings by successfully predicting experimental bacteria counts in scald water using the model developed herein. Also, we provide general guidelines for combating cross-contamination and improving overall microbiological quality at the scalding stage. In Section 5 we discuss the affects of $\mathrm{pH}$ and temperature on cross-contamination using the steady-state concentration of bacteria in scald water (see Section 5.1). Furthermore, we illustrate the applicability and relevance of our work by using Canadian processor survey data to give alternative scalding strategies and operating conditions (see Section 5.3). Finally, we provide directions for further study and call for specific future experiments needed to fill gaps in present knowledge and data (see Section 5.4).

\section{Thermal inactivation of C. jejuni}

\subsection{Experimental results}

The time to kill $90 \%$ of an initial population is called a decimal reduction time, or $D$-value. All available experimentally determined
C. jejuni D-values across six experiments have been compiled for this study, totaling 17 C. jejumi strains (Al Sakkaf and Jones, 2012; Doyle and Roman, 1982; Sorqvist, 1989; Blankenship and Craven, 1982; Waterman, 1982; Nguyen et al., 2006). These D-values give the killing rate of $C$. jejumi in neutral $\mathrm{pH}$ media such as brain-heart infusion broth (BHI) and skim milk. The high variation in killing rate with temperature is captured in Fig. 1A. While suspension temperature is crucial, $\mathrm{pH}$ also plays a pivotal role in bacteria inactivation (Bazin and Prosser, 1988; Humphrey and Lanning, 1987). As $\mathrm{pH}$ drifts away from neutral to acidic or alkaline, the rate of killing is increased (Bazin and Prosser, 1988). In other words, neutral $\mathrm{pH} 7$ is the highest point of thermal resistance (Bazin and Prosser, 1988). Experimental results of $C$. jejuni $\mathrm{D}$-values across the $\mathrm{pH}$ spectrum are shown in Fig. 1B. To further complicate the situation, scald water contains high levels of organic material (e.g. excreta, blood, fat, proteins, etc.), buffering the bacterial inactivation process (Humphrey and Lanning, 1987; Yang et al., 2001). If the processor accounts for the least sensitive strain (highest thermal resistance), then the remaining strains will also be inactivated. In Section 2.2, we provide an effective range which covers a wide variety of strains regardless of their individual thermal resistances. We invite the reader to see a more complete discussion regarding these items in AppendixB.1 and AppendixB.2.

\subsection{Determining inactivation rate during scalding process}

To gain insights into the scalding process, we develop a model accounting for the items mentioned above. Specifically, we wish to address:

1) The variation across experiments in killing rate versus temperature (Fig. 1A)

2) The effects of $\mathrm{pH}$ on thermal inactivation (Fig. 1B)

3) The buffering effects of organic material present in scald water (Yang et al., 2001).

To capture the combined effects of $\mathrm{pH}$ and temperature on Dvalues in scalding water, relative to each of the $17 \mathrm{C}$. jejuni strains from the available data, we propose the following inactivation model:

$$
D_{w_{i}}(p H, T)=D(p H)\left[D_{i}(T)\right]
$$

where $i$ refers to a particular $C$. jejuni strain, $T$ is the temperature of the scald water, and the forms of $D(p H)$ and $D_{i}(T)$ are dictated by experimental data (see Fig. $1 \mathrm{~A}$ and $\mathrm{B}$ ). In particular, we use $D(\mathrm{pH})=$
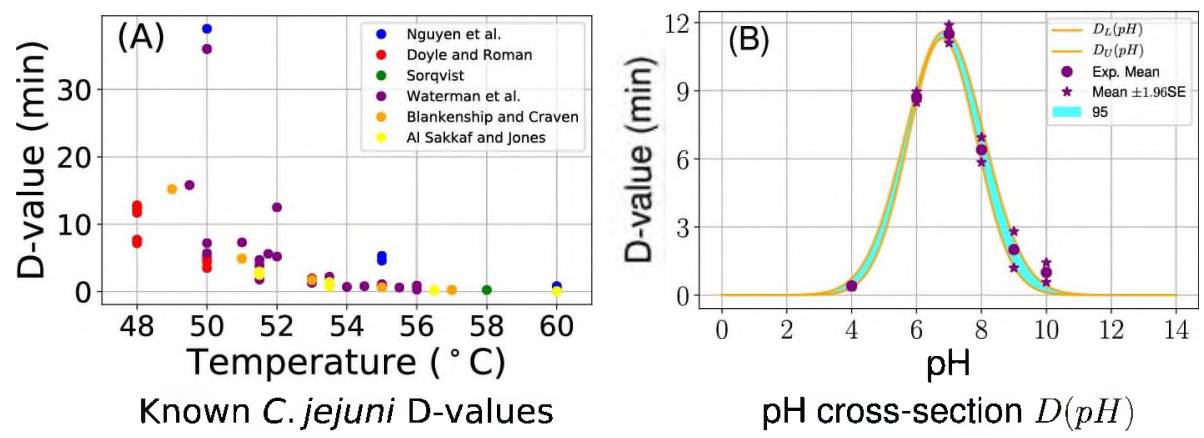

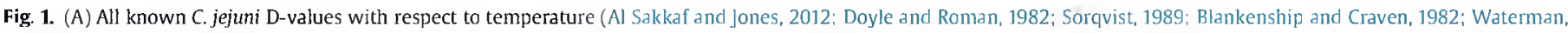

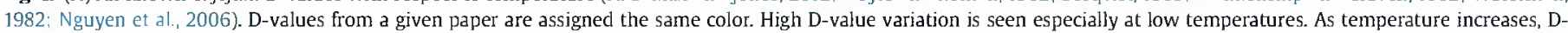

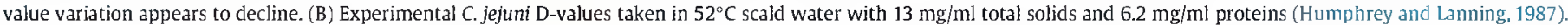

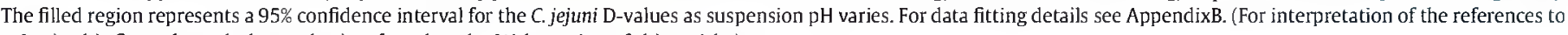
color in this figure legend, the reader is referred to the Web version of this article.) 


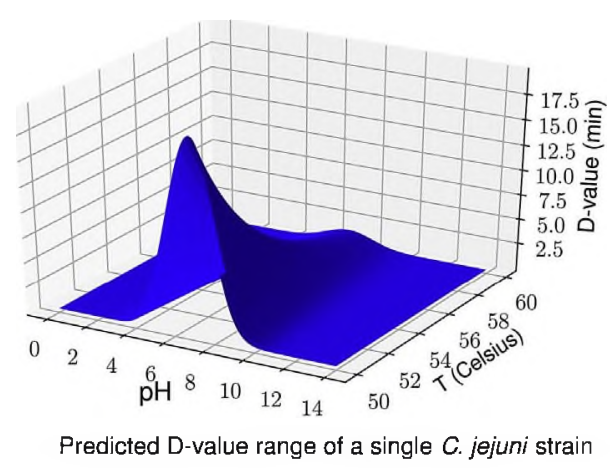

Fig. 2. Displayed is the predicted D-value range for a single $C$. jejumi strain, a building block of our inactivation model $D_{w}(p H, T)$. Essentially the cross-sections from a single strain's D-values vs. temperature with the D-value vs. pH cross-sectional area are combined in Fig. 1B. This can be seen by the Gaussian shape with $\mathrm{pH}$ and decaying exponential in temperature. By repeating this process for each of the $17 \mathrm{C}$. jejuni strains in Fig. 1A, we see lower and upper bounding surfaces arise naturally. Allowing $D_{w}(p H, T)$ to take all values between these lower and upper bounds takes into account all known experimental variation in C. jejuni kill rates, suspension $\mathrm{pH}$ effect on kill rate, and buffering effects of organic material present in scald water.

$\widehat{a} e^{-(\langle p H-\hat{b}) /(\widehat{c}))}$ and $D_{1}(T)=a_{i} e^{b_{i}\left(T-T_{\text {ref }}\right)}$. In order to determine the parameters $\widehat{a}, \hat{b}, \hat{c}, a_{i}$, and $b_{t}$, we use the data illustrated in Fig. $1 \mathrm{~A}$ and $\mathrm{B}$ to solve the respective least squares problems for $D_{t}(T)$ and $D(p H)$ (Humphrey and Lanning, 1987; Al Sakkaf and Jones, 2012; Doyle and Roman, 1982; Sorqvist, 1989; Blankenship and Craven, 1982; Waterman, 1982; Nguyen et al., 2006). Notice that for Dvalues as a function of $\mathrm{pH}$, we use the upper and lower bounds of the $95 \% \mathrm{CI}$ to solve the inverse problem for $D_{U}(p H)=a_{U} e^{\left.-\left(p H I-b_{U} / c_{U}\right)\right)^{2}}$ and for $D_{L}(p H)=a_{L} e^{-\left(\left\langle p H-b_{L} / c_{L}\right)\right)^{2}}$ (illustrated by the upper and lower curves, respectively in Fig. 1B).

In order for model (1) to be relevant during scalding, we scale the fitted parameters $a_{i}$ to be 1 so that

$D_{L}(p H) \leq D_{w i}\left(p H, T_{\text {ref }}\right) \leq D_{U}(p H)$.

With this scaling of $a_{i}$ and setting $T_{\text {ref }}=52^{\circ} \mathrm{C}$, we impose the condition that model (1) determined $\mathrm{D}$-values agree with the crosssection illustrated in Fig. 1B. The motivation for this is as follows: since the D-value vs. $\mathrm{pH}$ experiments take place in actual scald water at $52^{\circ} \mathrm{C}$ with high concentrations of organic material and proteins, we scale the $D_{t}(T)$ equation to agree with this data. These ideas are displayed graphically in Fig. 2. We repeat this process for all 17 C. jejuni strains; and, arising naturally are lower and upper bounds due to the spread in experimental data. To capture this experimental variation, we consider all $\mathrm{D}$-values between the upper and lower bounds. For each $\mathrm{pH}$ and temperature pair, $D_{w_{i}}(p H, T)$ gives precisely this full range of $C$. jejuni D-values and addresses key items 1),2), and 3) above. For the rest of the paper, instead of referring to $D_{w_{i}}$ in (1) for all 17 strains, we use the notation $D_{w}$ to account for the relevant range of inactivation values across all 17 strains. For more mathematical, data fitting, and model construction details concerning (1), please see AppendixB.3.

\subsection{Validation of inactivation model at $T_{\text {ref }}=52^{\circ} \mathrm{C}$}

Using data from two experimental results which estimate $C$. jejumi $D$-values taken from an industrial scald tank after four hours of continuous processing (Okrend et al.), we provide forward validation for model (1) at $T_{\text {ref }}=52^{\circ} \mathrm{C}$ for two different $\mathrm{pH}$ values. In scald water at $\mathrm{pH} 6.97$ a $D$-value of $10.93 \pm 2.87 \mathrm{~min}$ was reported at $52^{\circ} \mathrm{C}$ (Okrend et al.). At this temperature and $\mathrm{pH}$ value, model (1) predicts a $D$-value range of $D_{w}(6.97,52)=[11.14,11.57] \mathrm{min}$. Furthermore, in scald water treated with acetic acid ( $\mathrm{pH} 4.38)$, a $D$-value of $1.20_{ \pm}$ $0.45 \mathrm{~min}$ was estimated at $52{ }^{\circ} \mathrm{C}$ (Okrend et al.). Our inactivation model (1) predicts a $D$-value range of $D_{w}(4.38,52)=[0.81,1.45]$ min. Thus, in the case of $T_{\text {ref }}=52^{\circ} \mathrm{C}$, model (1) predictions show good agreement with the $D$-values determined from (Okrend et al.). Note that the data from (Okrend et al.) is not part of the original data sets from which model (1) was developed. What remains to be shown is the predictive capacity of model (1) at temperatures other than $T_{\text {ref }}=52^{\circ} \mathrm{C}$ in the context of industrial scalding. To do so, we develop a model for the scalding process that incorporates the inactivation model (1) as a key component.

\section{Scald model}

In this section we develop a scald model, based on a system of ordinary differential equations, in the context of an industrial setting that quantifies (i) bacteria levels in the scald water and (ii) bacteria levels on the surface of the carcasses. Models of this form have been successfully used to predict bacteria counts in process water at other stages of the poultry processing chain (e.g. immersion chilling (Munther et al., 2016; McCarthy et al., 2017; Sukted et al., 2017),). The incoming rate of carcass mass in $\mathrm{kg} / \mathrm{min}$ is $N$ and carcasses leave the scalder at rate $d_{s}(1 / \mathrm{min})$, i.e., $1 / d_{S}$ is the scald tank mean residence time in minutes. The mass of carcasses in the scald tank is assumed to be constant at $P=N / d_{s}(\mathrm{~kg})$ after $1 / d_{s}$ min of scalding operation. Note that scald time, or duration, is typically 1-2 min. Lastly, the scald tank has volume $T_{V}$ (liters).

The viable $C$. jejuni averaged over all resident scald carcasses is given by $v_{p}$ (CFU/carcass). Bacterial loads vary from carcass to carcass, so we consider an average load over all incoming carcasses $\sigma(\mathrm{CFU} / \mathrm{kg})$ to be constant. While there is variation of input contamination due to transmission within flocks and also between flocks ( $\mathrm{FAO} / \mathrm{WHO}, 2009$ ), we assume an average over all these variations $\sigma$ is constant. With the average contamination $\sigma$ and a constant rate of carcasses entering the tank, the rate of incoming viable bacteria may be written $\sigma N$, where $m_{c}$ is the mass of a typical broiler chicken. We also consider bacteria shedding from carcass surfaces to scald water at rate $k_{c W}(1 / \mathrm{min})$ and thermal inactivation on carcass surfaces at rate $I_{c}(1 / \mathrm{min})$. Hence we have $v_{p}=\frac{m_{c} g N}{p}-k_{c w} v_{p}-I_{c} v_{p}-d_{s} v_{p}$, where - indicates the derivative with respect to time.

Our model also considers viable bacteria in scald water $W$ (CFU/ $\mathrm{ml}$ ). Bacteria shedding from surfaces of carcasses to the water occurs at rate $\frac{k_{\delta_{W} v_{p} P}}{10 T_{v} m_{i}}$. Bacteria present in scald water is inactivated at rate $I_{w}(1 / \mathrm{min})$. Because $I_{w}$ depends on both the $\mathrm{pH}$ and temperature of the scald water in question, we utilize model (1), defining $I_{w}=\ln (10) / D_{w}(p H, T)$. Thus, $I_{w}$ reflects a range, determined by $D_{w}(p H, T)$, which contains the effective kill rate of $C$. jejuni in scald water at a fixed $\mathrm{pH}$ and temperature. Finally, scald water overflow (and replenishment) occurs at rate $\mathrm{g}(\mathrm{L} / \mathrm{min})$, indicating that bacteria leave at rate $g / T_{V}(1 / \mathrm{min})$. Putting these pieces together, we

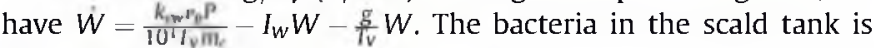
taken to be initially zero as no carcasses have entered at $t=0$. Similarly, we assume that no bacteria are present in the scald water prior to scalding. As a result we impose the initial conditions $v_{p}(0)=0$ and $W(0)=0$ for the following system:

$$
\left\{\begin{array}{cc}
\dot{v}_{p}=\frac{m_{c} \sigma N}{P}-k_{c w} v_{p}-I_{c} v_{p}-d_{s} v_{p}, & v_{p}(0)=0, \\
\dot{W}=\frac{k_{c w} \nu_{p} P}{10^{3} T_{V} m_{c}}-I_{W} W-\frac{g}{T_{V}} W, & W(0)=0, \\
I_{W}=\ln (10) / D_{W}(p H, T) . &
\end{array}\right.
$$




\subsection{Model properties and steady states}

The scald model (3) is well-posed mathematically. In other words, we have existence and uniqueness of solutions for (3). It can easily be shown that for non-negative initial conditions, solutions may be found which remain positive and bounded. Therefore solutions associated with non-negative initial conditions capture relevant bacterial levels in time. Note that model (3) is linear, hence closed form solutions may be easily found. In particular, we are interested in the steady states of model (3). The unique positive steady state of (3), $\left(v_{p}^{*}, W^{*}\right)$ is given below in (4). Using standard techniques, this steady state can be shown to be globally asymptotically stable for biologically relevant solutions (i.e., solutions associated with non-negative initial conditions).

$$
\begin{aligned}
& v_{p}^{*}=\frac{m_{c} \sigma N}{P\left(k_{c w}+I_{c}+d_{s}\right)} \\
& W^{*}=\frac{k_{c w} v_{p}^{*} P}{10^{3} T_{V} m_{C}\left(I_{W}+\frac{g}{T_{V}}\right)}
\end{aligned}
$$

Since the data used to validate scald model ( 3 ) (see Section 4) is taken from an industrial scald operation that is at steady state, (4) is instrumental in the analysis that follows (Osiriphun et al., 2012).

\subsection{Scald process parameters}

Model (3) is constructed from two main types of mechanisms: (I) those that involve typical processing procedures for industrial scalding and (II) bacteria transfer and inactivation. Parameters, along with relevant values/ranges, corresponding to Type I or Type II mechanisms are categorized below. Parameter values/ranges are determined from a relatively complete set of scalding tank specifications and experimental $C$. jejuni counts from a plant in Thailand (Osiriphun et al., 2012).

Determination of Type I parameters: Scalding specifications are as follows: scald water $\mathrm{pH}$ is 8 , tank volume $T_{V}$ is $5900 \mathrm{~L}$, scald water outflow rate $\mathrm{g}$ is $172 \mathrm{~L} / \mathrm{min}$, and carcass residence time in the scalding tank is 1.85 min (Osiriphun et al., 2012). Since carcass residence time is $1.85 \mathrm{~min}$, the rate at which carcasses leave the scalder is $1 / 1.85 \mathrm{~min}$, i.e. $d_{\mathrm{s}}=1 / 1.85(1 / \mathrm{min})$. We find incoming carcass mass $N$ using line processing speed and average carcass mass $m_{c}$. Line speed is reported to be 200 birds per minute (Osiriphun et al., 2012). Although carcass mass is not reported, typical broiler carcass mass is $2 \mathrm{~kg}$. As a result $N=200 m_{c}=400 \mathrm{~kg} / \mathrm{min}$. Note that experiments were conducted with scald water at $54.15^{\circ} \mathrm{C}$ (Osiriphun et al., 2012). For the remainder of Section 3, we fix the temperature at $54.15^{\circ} \mathrm{C}$ and determine ranges for Type II parameters as follows.

Determination of Type II parameters: The average of measured C. jejuni pre-scald counts were $10^{8} \mathrm{CFU} /$ carcass for the $54.15^{\circ} \mathrm{C}$ scalding experiment, so we estimate $\sigma=5 \times 10^{7} \quad \mathrm{CFU} / \mathrm{kg}$ (Osiriphun et al., 2012). For $C$. jejuni inactivation in the scald water with $\mathrm{pH} 8$ and temperature $T=54.15^{\circ} \mathrm{C}$, using the last equation in (3), we calculate that $I_{w}(8,54.15) \in[0.54,2.82](1 / \mathrm{min})$.

Using methods found in (Osiriphun et al., 2012) and the calculated range for $I_{w}(8,54.15)$, we calculate the bacteria shed rate from carcass surfaces $k_{C W}$ and the rate of $C$. jejuni thermal surface inactivation $I_{c}$. In particular, we first find $k_{c} w+I_{c}$ using pre-scald and post-scald experimental counts in (Osiriphun et al., 2012). Next we inform the mass balance found in (Osiriphun et al., 2012) with $I_{W}(8,54.15)$ calculated above, processing specifications in Table 1 , and scald water counts taken from samples during a $54.15^{\circ} \mathrm{C}$ scald in (Osiriphun et al., 2012). This allows us to find $k_{c w} /\left(k_{c w}+I_{c}\right)$ and then subsequently ranges for $k_{C W}$ and $I_{C}$. Carrying out this process
Table 1

Parameter values and ranges from Section 3.2

\begin{tabular}{llll}
\hline Name & Type I parameters & Value/Range & Units \\
\hline$T_{V}$ & Scald tank volume & 5900 & $\mathrm{~L}$ \\
$\mathrm{~g}$ & Water overflow & 172 & $\mathrm{~L} / \mathrm{min}$ \\
$d_{S}$ & Carcass exit rate & $1 / 1.85$ & $1 / \mathrm{min}$ \\
$m_{C}$ & Typical carcass mass & 2 & $\mathrm{~kg}$ \\
$N$ & Rate of incoming poultry mass & 400 & $\mathrm{~kg} / \mathrm{min}$ \\
$\mathrm{pH}$ & pH of scald water & 8 & \\
$\mathrm{~T}$ & Temperature of scald water & 54.15 & ${ }^{\circ} \mathrm{C}$ \\
\hline & Type II parameters & & \\
\hline$I_{w}$ & Scald water thermal kill rate at & {$[0.54,2.82]$} & $1 / \mathrm{min}$ \\
& pH 8 and $54.15^{\circ} \mathrm{C}$ & & \\
$k_{C w}$ & Carcass to water bacterial shed rate & {$[0.31,1.55]$} & $1 / \mathrm{min}$ \\
$I_{C}$ & Carcass thermal surface kill & {$[0.74,1.98]$} & $1 / \mathrm{min}$ \\
$\sigma$ & Input $C$. jejuni load & $5 \times 10^{7}$ & $\mathrm{CFU} / \mathrm{kg}$ \\
\hline
\end{tabular}

we find $I_{C} \in[0.74,1.98] 1 / \mathrm{min}$ and $k_{C W} \in[0.31,1.55] 1 / \mathrm{min}$. Notice that the range for $I_{C}$ as compared with $I_{W}$ is reasonable as $I_{W}$ should in general exceed $I_{c}$ (Osiriphun et al., 2012).

\subsection{Transient dynamics}

We investigate the transient dynamics of (3) using parameter values/ranges from Table 3.3 (i.e. in the context of $\mathrm{pH}=8$ and scald water temperature $T=54.15^{\circ} \mathrm{C}$ ). For parameter sampling and simulation details, see the caption in Fig. 3 as well as AppendixC. The results are depicted in Fig. 3 for the first 30 min of a ( $8+$ hour) scalding shift. The system rapidly approaches steady state (within minutes), and as a result, the steady state (4) is an excellent approximation for the model (3) over a working day. A similar transient time may be found analytically by non-dimensionalizing the model (3).

\section{Validation of the scald model}

We validate model (3) by comparing its prediction of $C$. jejuni levels in the scald water against the experimental data in (Osiriphun et al., 2012) for scald water with $\mathrm{pH}=8$ and temperature $T=61.08^{\circ} \mathrm{C}$. In particular, we use the steady state equation (4) to compare the predicted $C$. jejuni counts in the scald water $\left(W^{*}\right.$ at $T=61.08^{\circ} \mathrm{C}$ ) with the measured counts coming from (Osiriphun et al., 2012). The justification for using the steady state equation (4) is as follows: notice that the transient time for the model (3) solutions to reach steady state, in the $T=54.15^{\circ} \mathrm{C}$ context, is on the order of minutes (see Fig. 3). In the $T=61.08^{\circ} \mathrm{C}$ context, the transient time for the model (3) solutions are even shorter. Recall that the convergence rate of the (3) solutions $\nu_{p}(t)$ and $W(t)$ to steady state depends on the magnitude of the parameter combinations $I_{w}+g / T_{V}$ and $k_{C w}+I_{C}+d_{s}$ respectively. At the higher temperature $T=61.08^{\circ} \mathrm{C}, I_{w}$ and $I_{c}$ increase in magnitude and therefore reduce the transient time. The overflow rate $g / T_{V}$ and carcass residence time in the scalder $d_{s}$ do not change (Osiriphun et al., 2012). Furthermore, we argue that the range of bacteria shed rate, $k_{c w}$, determined by the calculations in Section 3.2 at $T=54.15^{\circ} \mathrm{C}$, should not change significantly at $T=61.08^{\circ} \mathrm{C}$ as this rate depends more on the shear forces in scald water.

The steps for validation of (3) at $\mathrm{pH} 8$ and $T=61.08^{\circ} \mathrm{C}$ are as follows: (i) Using the pre/post scald $C$. jejuni counts on carcasses from (Osiriphun et al., 2012) we calculate that $k_{c w}+I_{c}=2.28$ (1/ min). (ii) Next, because $k_{c w} \in[0.31,1.55](1 / \mathrm{min})$; we determine that $I_{c} \in[1.79,3.03](1 / \mathrm{min})$; (iii) Using these ranges, we calculate $v_{p}$ from (4) and then substitute the resulting values into the equation for $W^{*}$ from (4). For $k_{c W}=0.31$, model (3) predicts that $W^{*} \in[0.15,74] \mathrm{CFU} / \mathrm{ml}$ and for $k_{\mathrm{c} W}=1.55, W^{*} \in[0.75,368] \mathrm{CFU} / \mathrm{ml}$. The measured $C$. jejuni count in the scald water from (Osiriphun 


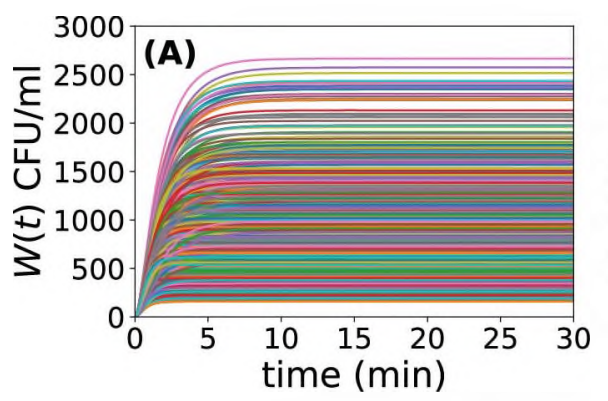

Time dynamics of $W$

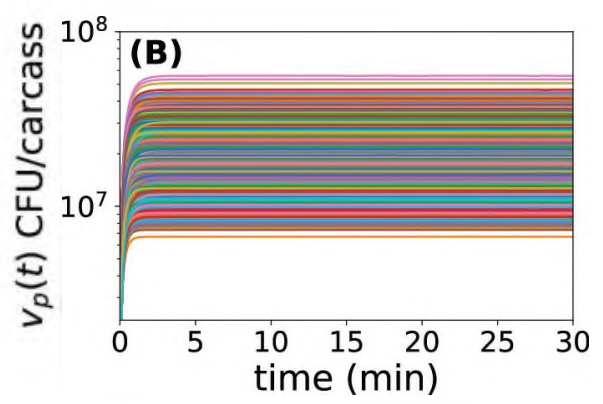

Time dynamics of $v_{p}$

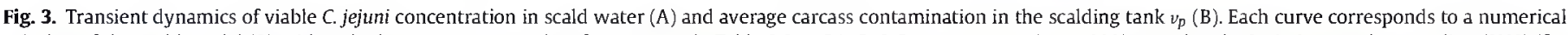

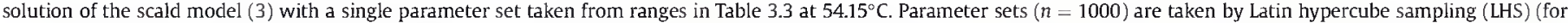

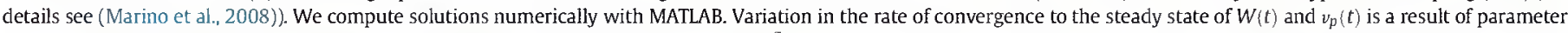

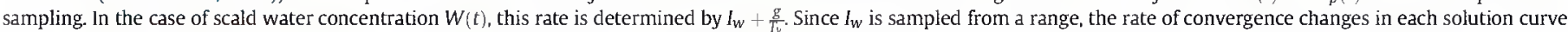

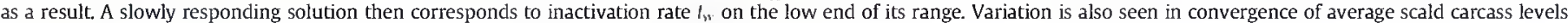
$v_{p}(t)$, determined by rate $k_{c w}+I_{c}+d_{s}$, i.e., the average rate bacteria leaves compartment $v_{p}$.

et al., 2012) was $24.5 \mathrm{CFU} / \mathrm{ml}$, showing good agreement with the predicted $W^{*}$ ranges from model (3). We expect that the measured bacteria levels should be on the low end of our predicted ranges for $W^{*}$ as total solids (TS) counts were low $(2 \mathrm{mg} / \mathrm{ml}$ reported in (Osiriphun et al., 2012) and typical TS counts in the scalding tank are $2-8 \mathrm{mg} / \mathrm{ml}$ (Cason et al., 1999)). Hence buffering effects of organic material on $C$. jejuni killing were limited (Yang et al., 2001).

The above validation raises a number of points. In addition to directly justifying the predictive capacity of model (3), it provides additional justification for the inactivation model (1) in scald water. In particular, it supports the notion that a Gaussian relationship (with respect to varying $\mathrm{pH}$ ) at temperatures other the than $T_{\text {ref }}=52^{\circ} \mathrm{C}$ is adequate to capture inactivation in scald water. Furthermore, model (3) can aid experimental approaches to explore this claim more rigorously. That is, model (3) can provide a reference point against which to compare experimental results subject to different scalding specifications as well as varying incoming bacteria loads on carcasses. This type of tool is crucial in an industry where experimental data is difficult to synthesize. Finally, we note that the parameter estimation technique outlined in Section 3.2 informed by our inactivation model (Section 2 ) gives estimates for $C$. jejuni inactivation on carcass surfaces $\left(I_{C}\right)$ during scalding as a function of $\mathrm{pH}$ and temperature. Such rates would be difficult to determine directly from experimentation alone.

\section{Discussion}

\subsection{Implications of $W^{*}$ variation for cross-contamination}

The dependence of $W^{*}$ on the inactivation rate $I_{W}$ gives insight toward situations for which cross-contamination in the scalding process are most likely. It is reasonable to assume that bacteria attach to carcass surfaces at a rate proportional to the $C$. jejuni concentration in the scald water (Osiriphun et al., 2015). Due to the fact that C. jejumi is inactivated more slowly in neutral $\mathrm{pH}$ scald water than in acidic or alkaline scald water, cross-contamination becomes more prevalent at neutral $\mathrm{pH}$. While cross-contamination is most prevalent at neutral $\mathrm{pH}$ for a given temperature, scald water temperature still plays a pivotal role due to the dependence of $W^{*}$ on $I_{W}$. Note that $W^{*}$ is essentially inversely proportional to $I_{w}$ due to the relative size of $I_{w}$ compared to $g / T_{V}$ (see scald model steady state equation (4)). We see experimental evidence of this throughout literature. For example, in (Osiriphun et al., 2012) raising temperature from $54.15^{\circ} \mathrm{C}$ to $61.08^{\circ} \mathrm{C}$ while $\mathrm{pH}$ remained constant at 8 resulted in lower viable $C$. jejuni concentration in scald water (from $794 \mathrm{CFU} / \mathrm{ml}$ to $24.5 \mathrm{CFU} / \mathrm{ml}$ ). Hence the dangers of cross-contamination are highest at neutral $\mathrm{pH}$ values and low operating scald temperatures. Additionally, these findings are also in agreement with experimental results in (Lillard et al., 1987).

\subsection{Potential risks and side-effects of manipulating scalding $p H$ with additives}

Although cross-contamination, bacteria counts, and prevalence at a given operating temperature may be reduced by adjusting the $\mathrm{pH}$ of scald water, the risks and effects of additives must be weighed. Carcass skin color, skin quality, ease of feather removal post-scald, poultry plant safety, etc. all depend on scald water pH (Humphrey and Lanning, 1987). Skin color and quality are optimal at pH 8.5 (Humphrey and Lanning, 1987). Feather removal becomes more difficult at $\mathrm{pH}$ values above 9.5 (Humphrey and Lanning, 1987). Alkaline additives such as $\mathrm{NaOH}$ have caused sickness to workers as a result of the high concentrations of ammonia released (Humphrey and Lanning, 1987). McKee et al. note the possible danger of using alkaline additives in scalding as they could inactivate chlorine in the subsequent chilling process (McKee et al., 2008). Consideration for cost and availability of additives must also be taken into account (Okrend et al.). Thus care must be taken in deciding the best course of action for combating cross-contamination while keeping the risks at a minimum in other regards.

\subsection{Application to canadian processors}

We demonstrate the applicability of our $C$. jejuni inactivation model using results of an unpublished 2012-2013 processor survey from The Canadian Poultry and Egg Processors Council. Scald water temperature and $\mathrm{pH}$ is given in Table 2 for seven industrial plants in Canada. Alongside the processing data, we include ranges for C. jejuni killing rate $I_{w}(p H, T)$ for the scalding configuration. There is high variation for inactivation $I_{w}(p H, T)$ across the seven plants. Note plants A,D,G likely use chemical additives as their $\mathrm{pH}$ is extreme relative to tap water. Plants $A, D, G$ also have far higher inactivation rates as they avoid the $\mathrm{pH} 7$ danger zone where thermal resistance is maximum (Humphrey and Lanning, 1987; Okrend et al.; Bazin and Prosser, 1988). Plants A and B implement a costeffective strategy in using the first scalding tank to merely remove organic material from birds, then subsequent high temperature scald to rapidly inactivate bacteria (see Table 3 ).

We provide a simple illustrative example showing the application 
Table 2

Parameter values and ranges from Section 4 used for model validation.

\begin{tabular}{|c|c|c|c|}
\hline Name & Type I parameters & Value/Range & Units \\
\hline$T_{V}$ & Scald tank volume & 5900 & $\mathrm{~L}$ \\
\hline$g$ & Water overflow & 172 & $\mathrm{~L} / \mathrm{min}$ \\
\hline$d_{S}$ & Carcass exit rate & $1 / 1.85$ & $1 / \mathrm{min}$ \\
\hline$m_{c}$ & Typical carcass mass & 2 & kg \\
\hline$N$ & Rate of incoming poultry mass & 400 & $\mathrm{~kg} / \mathrm{min}$ \\
\hline $\mathrm{pH}$ & $\mathrm{pH}$ of scald water & 8 & \\
\hline \multirow[t]{2}{*}{$\mathrm{T}$} & Temperature of scald water & 61.08 & ${ }^{\circ} \mathrm{C}$ \\
\hline & Type II parameters & & \\
\hline$I_{w}$ & Scald water thermal kill rate at $\mathrm{pH} 8$ and $61.08^{\circ} \mathrm{C}$ & {$[3.30,1628.95]$} & $1 / \min$ \\
\hline$k_{\text {rw }}$ & Carcass to water bacterial shed rate & {$[0.31,1.55]$} & $1 / \min$ \\
\hline$I_{c}$ & Carcass thermal surface kill at $\mathrm{pH} 8$ and $61.08^{\circ} \mathrm{C}$ & {$[1.79,3.03]$} & $1 / \min$ \\
\hline$\sigma$ & Input C. jejuni load & $4.5 \times 10^{7}$ & $\mathrm{CFU} / \mathrm{kg}$ \\
\hline
\end{tabular}

Table 3

Scalding temperature and $\mathrm{pH}$ information from a survey of industrial poultry plants in Canada taken between December 1, 2012 and December $31,2013$.

\begin{tabular}{|c|c|c|c|}
\hline \multirow[t]{2}{*}{ Plant } & Temperature in ${ }^{\circ} \mathrm{C}(\mathrm{pH})$ [Range on $I_{w}$ ] & \multirow[t]{2}{*}{ Scald tank 2} & \multirow[t]{2}{*}{ Scald tank 3} \\
\hline & Scald tank 1 & & \\
\hline A & $51.67(9)[\approx 1]$ & $53.33(9)[1.3,6.2]$ & $58.89(9)[5.6,1017.5]$ \\
\hline $\mathrm{B}$ & $34(7.83)[\approx 0]$ & $60(7.83)[2.2 .509 .3]$ & \\
\hline C & $58.5(7)[1.1,80.8]$ & & \\
\hline $\mathrm{D}$ & $58.33(5)[3.3,289.9]$ & & \\
\hline $\mathrm{E}$ & $58.3(7)[1.0,67.3]$ & & \\
\hline $\mathrm{F}$ & $61.1(6.7)[2.2,864.8]$ & & \\
\hline G & $58.3-58.89(4)[18,3841.2]$ & & \\
\hline
\end{tabular}

of inactivation model $I_{w}(p H . T)$. With the link between temperature and $\mathrm{pH}$, we provide alternatives to several of the Canadian poultry plants in Table 2. Primary items to consider regarding cost-effective scalding are energy prices for heating scald water and prices of chemical additives. As a result, plant-specific control problems of maximizing of $I_{w}(p H, T)$ while minimizing costs may be posed.

Plant A maintains high $\mathrm{pH}$ in all three tanks through use of additives. However, in the first stage we see low inactivation rates $I_{w}(p H, T)$. A low kill rate combined with a high amount of organic material typically seen in the first stage (details in (Cason et al., 1999)) will result in buffering an already low inactivation rate. It may be more effective to discontinue use of additives in tank 1 , keeping the $\mathrm{pH}$ high in tanks 2 and 3. After all, the vast majority of inactivation takes place in the hotter, latter stages with little buffering effects from organic material. The increased $\mathrm{pH}$ in the high temperature tanks take advantage of the synergistic effect, that is, the combination of extreme $\mathrm{pH}$ environment and high temperature (McKee et al., 2008). Plant B may benefit from a similar strategy.

Plants $\mathrm{E}$ and $\mathrm{F}$ conduct scalding at high temperature at a neutral $\mathrm{pH}$. While plants $\mathrm{E}$ and $\mathrm{F}$ maintain a high inactivation rate, we provide two alternatives which may improve end-result microbiological quality and also prove cost-effective. For example, plant E could maintain a similar inactivation rate using additives while operating at a lower temperature. For instance, consider $\mathrm{pH} 9.3$ together with a (lower) temperature of $55.3^{\circ} \mathrm{C}\left(I_{w}(9.3,55.3) \in[3.5,71.4]\right)$ and $\mathrm{pH} 4$ at $54.5^{\circ} \mathrm{C}\left(I_{w}(4,54.5) \in[6,68.4]\right)$. Thus the increase of the lower bound inactivation rate and lower scald temperature may result in a higher quality end product as the epidermis is removed in high temperature scalding. For plant $\mathrm{F}$ we may suggest lowering the temperature slightly and maintaining an acidic or alkaline $\mathrm{pH}$ environment. To maintain a similar kill rate, plant $\mathrm{F}$ may consider pH 9.3 at $58^{\circ} \mathrm{C}$ $\left(I_{w}(9.3,58) \in[7,850.7]\right)$ or $\mathrm{pH} \quad 4.1$ at $57.5{ }^{\circ} \mathrm{C}$ $\left(I_{w}(4.1,57.5) \in[10.9,837.6]\right)$. Again, notice the lower bound on inactivation increases significantly while keeping a similar upper bound. Lowering the temperature while maintaining $\mathrm{pH}$ in a reasonable range may result in a higher quality skin appearance while being cost-effective.

\subsection{Conclusions and future directions}

The foundational papers of Lillard et al. (1987), Okrend et al. Okrend et al., Humphrey and Lanning (1987) are summarized in Section AppendixA. These works all note that cross-contamination may be reduced by introducing acidic or alkaline additives to scald water. While our findings are in agreement with these works, it is important to note that our work expands on this idea. In particular. we quantify how the bacteria level in the scald water $W$ is linked to $\mathrm{pH}$ and temperature via model (3). While $\mathrm{pH}$ is certainly important, we illustrate how the temperature, $\mathrm{pH}$ pair determines the $C$. jejumi kill rate in scald water. As the magnitude of $W$ is directly related to cross-contamination, in effect, our model (3) provides a quantifiable connection between the temperature, $\mathrm{pH}$ pair and potential for cross-contamination.

In terms of control, this quantitative link (via $I_{W}(p H, T)$ ) is applicable in a HACCP context, suggesting that the $\mathrm{pH}$ - temperature pair is a critical control parameter in the scalding stage. Previous works have experimentally verified the thermal resistance of $C$. jejumi and other heat-sensitive bacteria to be highest in a neutral $\mathrm{pH}$ environment (Humphrey and Lanning, 1987; Okrend et al.). USDA best practice recommendations suggest maintaining scald water pH below 6.5 or above 7.5 (Bennett, 2008). Our work may be used to further inform these recommendations as model (3) quantifies the synergistic role temperature and $\mathrm{pH}$ play in $\mathrm{C}$. jejuni inactivation, especially in light of given performance standards or maximum acceptable pathogen levels. As demonstrated in Section 4, model (3) adequately captures the mechanisms involved with $C$. jejuni kill rates in scald water. Note that some inactivation models, developed for different types of bacteria in media differing from that of scald water, have employed terms to further specify the pH-temperature effect on inactivation (Cerf et al., 1996; Gaillard et al., 1998). With detailed scalding experiments, quantifying $C$. jejuni D-values relative to multiple $\mathrm{pH}$ temperature pairs, it would be important to see if increased model complexity is necessary in the scalding context. Armed with such predictive confidence, the implementation of model (3) (or model (3) with an augmented inactivation term) into quantitative microbial risk 
assessment (QMRA) models, may also give insights into new riskmanagement strategies, and provide valuable information for policy-making.

In terms of pre-scald contamination, the model (3) considers a fixed, average rate of incoming bacteria on all carcasses $\sigma$. Realistically there is variation in the incoming bacteria levels on each bird (FAO/WHO, 2009). An individual-based model could take into account experimental flock prevalence and counts by varying $\sigma$ in time. It is then possible to quantify the spread of highly contaminated birds to their neighbors. Our model (3), parameter estimation, and thermal inactivation bounds on $I_{w}(p H, T)$ may inform such an individual-based model.

Further investigation of the impact of solids and organic material concentrations present in scald water on inactivation rates could give a clearer picture of bacteria inactivation in scalding. We propose that an experiment determining $C$. jejuni D-values in the presence of varying organic material concentrations relevant to scalding, similar to that in (Yang et al., 2001), would be significant. The typical concentrations of organic material in scalding water are $2-8 \mathrm{mg} / \mathrm{ml}$ (Cason et al., 1999). With this experimental information, data fitting and inactivation model construction techniques presented in Section 2 may be utilized to leverage these findings.

\section{Acknowledgements}

The authors give much thanks to Public Health Agency of Canada and Canadian Poultry and Egg Processors Council for providing us a 2012-2013 poultry processor survey. In addition, the authors sincerely thank the anonymous reviewers for their careful reading and helpful suggestions for improving the exposition of the article.

\section{Appendix A. Review: experiments using additives}

Appendix A.1pH influence on carcass and scalding water microbiological quality

We present a review of key experiments which study the effects of scald water $\mathrm{pH}$ on microbiological quality at the scalding stage. Experiments in (Humphrey and Lanning, 1987) and (Berrang et al., 2011) compare high $\mathrm{pH}$ (alkaline) scalding to the natural $\mathrm{pH}$ which tends to be neutral. On the other hand, (Okrend et al.) and (Lillard et al., 1987) compare low $\mathrm{pH}$ (acidic) scalding to a typical neutral $\mathrm{pH}$ control. Scald water $\mathrm{pH}$ is modified via additives such as calcium hydroxide (alkaline), sodium hydroxide (alkaline), acetic acid (acidic), and more recently peracetic acid (acidic). Scald water bacteria concentrations and prevalence are significantly reduced in (Humphrey and Lanning, 1987) within the high pH group. Significant reduction in carcass sample prevalence and concentrations are also seen in (Humphrey and Lanning, 1987) and (Berrang et al., 2011). The interested reader is invited to see the details in below in Section AppendixA.2, which include experimental procedures, bacteria counts, and prevalence.

\section{Appendix A.2Review: scald water $\mathrm{pH}$ influence in scalding}

Humphrey and Lanning (1987), Berrang et al. (2011). compare prescald and post-scald Campylobacter prevalence on carcasses sent through scald tanks operating at (i) high $\mathrm{pH}$ and (ii) conventional (control) $\mathrm{pH}$. Berrang et al. raise the $\mathrm{pH}$ of scald water through the addition of calcium hydroxide $\left(\mathrm{Ca}(\mathrm{OH})_{2}\right)$ while Humphrey and Lanning raise scald water $\mathrm{pH}$ with sodium hydroxide $(\mathrm{NaOH})$. Berrang et al. find a significant reduction in Campylobacter positive carcass prevalence (\%) and also mean concentration in rinse samples (log $\mathrm{CFU} / \mathrm{ml}$ ) in a high $\mathrm{pH}$ scald (mean $\mathrm{pH}$ 9.89) compared to control scald (mean pH 6.88). Pre-scald carcass prevalence of control and high $\mathrm{pH}$ groups were both $90 \%$, while post-scald prevalence of the control and high pH groups were $57 \%$ and $17 \%$, respectively. Pre-scald carcass rinse samples of both control and high pH groups contained $3.28 \log \mathrm{CFU} /$ $\mathrm{ml}$, whereas control and high $\mathrm{pH}$ groups contained 1.15 and $0.44 \log \mathrm{CFU} / \mathrm{ml}$ after scalding, respectively. Similar results were reported by Humphrey and Lanning. In Berrang et al., scald water in control group had mean $\mathrm{pH} 6.4$ and high $\mathrm{pH}$ group scald water had mean $\mathrm{pH} 9.18$. A $60 \%$ reduction of $C$. jejuni positive skin samples was observed. Hence we see a significant reduction of carcass contamination and prevalence by changing only scald water operating $\mathrm{pH}$. Humphrey and Lanning also compared $C$. jejuni prevalence and most probable number (MPN) in scald water for both control and high $\mathrm{pH}$ scald water. 12 of the 15 scald water samples in the control group were C. jejuni positive. On the other hand, 4 of the 15 high $\mathrm{pH}$ scald water samples were $C$. jejuni positive. Reduction in C. jejumi MPN from 82.3/ $100 \mathrm{ml}(823 \mathrm{MPN} / \mathrm{ml})$ to $1.5 / 100 \mathrm{ml}(15 \mathrm{MPN} / \mathrm{ml})$ was reported in control and high $\mathrm{pH}$ scald water samples. Hence we see that the addition of $\mathrm{NaOH}$ reduced MPN and prevalence significantly - an artifact of inactivation rates increasing as $\mathrm{pH}$ moves away from neutral.

On the acidic side of the $\mathrm{pH}$ spectrum, Okrend et al. (Okrend et al.) and Lillard et al. (1987). experiment with acetic acid as a scalding additive and in particular its impact on microbiological quality of scald water and carcass surfaces. Lillard et al. measure Salmanellae, Enterobacteriaceae, and total aerobic bacteria in additive-free scald water (control pH 6.9) and also with $0.5 \%$ acetic acid ( $\mathrm{pH}$ 3.6). Post-scald (unpicked) bacteria quantity for control and acetic acid treated groups are also provided. In contrast to the studies of Berrang et al. and Humphrey and Lanning, the carcass surface aerobic bacteria count, Enterobacteriaceae count, and Salmonellae prevalence (\%) all fail to reduce significantly with the use of $0.5 \%$ acetic acid. On the other hand, total aerobic bacteria and Enterobacteriaceae were reduced significantly in scald water by the presence of $0.5 \%$ acetic acid in the treatment group. None of the scald water samples were Salmonellae positive in both control and acetic acid treated groups. Lillard et al. note bacteria are protected by feathers, fecal matter, and skin in such a way that buffered acetic acid's effect on inactivation rate. Lillard concludes by noting the use of acetic acid for controlling cross-contamination in scalding due to the decrease in pathogens in scald water, but not to reduce carcass surface contamination. Note this is in contrast to the findings of Berrang et al., Humphrey and Lanning, who find significant reductions in surface contamination. Okrend et al. experimentally determine D-values of $C$. jejuni in untreated scald water ( $\mathrm{pH}$ 6.97) and scald water treated with $0.1 \%$ acetic acid ( $\mathrm{pH} 4.38$ ). Untreated scald water yielded a D-value of $5.97 \mathrm{~min}$ while $0.1 \%$ acetic acid treated scald water yielded a lower D-value of $1.20 \mathrm{~min}$.

\section{Appendix B. Supplementary material to section 2}

\section{AppendixB.1. Fixed-pH, temperature varying experiments}

Campylobacter jejumi decimal reduction times at varying temperatures are found in the papers of Sakkaf and Jones (Al Sakkaf and Jones, 2012), Doyle and Roman(1982), Sorqvist(Sorqvist, 1989), Blankenship and Craven (1982), Waterman (1982), and Nguyen et al.(2006). In total there are D-values provided for $17 \mathrm{C}$. jejumi strains across these six works and are displayed graphically in Fig. 1A. While heating menstruum (and therefore $\mathrm{pH}$ ) change between papers, the heating menstruum remains constant within each paper's experiments. Even so, we see vast differences in the reports of decimal reduction times for C. jejuni with respect to temperature across these six papers. We see a high variation in kill rates especially in the lower temperature ranges; as temperature increases this variation appears to decreases. Doyle and Roman report D-values of 3.5-5.1 min at $50^{\circ} \mathrm{C}$ for all five $\mathrm{C}$. jejuni 
strains in their experiments Doyle and Roman (1982). On the other hand, Nguyen et al. report D-values of 36-39 min with 2 strains of C. jejuni at $50^{\circ} \mathrm{C}$ (Nguyen et al., 2006). These near ten-fold differences could be attributed to Doyle and Roman using skim milk ( $\mathrm{pH} \mathrm{6.8)} \mathrm{as}$ heating menstruum and Nguyen et al. using heart infusion broth $(\mathrm{pH}$ 7.4) (Nguyen et al., 2006; Doyle and Roman, 1982). In other words, strain heat sensitivity, experimental method, and variables such as heating menstruum may greatly impact the inactivation of $C$. jejuni. However we see that Doyle and Roman, Blankenship and Craven, Waterman, and Sorqvist all report tight D-value ranges over the relevant scalding temperature spectrum (Waterman, 1982; Sorqvist, 1989; Blankenship and Craven, 1982; Doyle and Roman, 1982). For example, at $55^{\circ} \mathrm{C}$ all such D-values found by Doyle and Roman, Blankenship and Craven, Waterman, and Sorqvist were between 0.47 and $1.14 \mathrm{~min}$ despite slightly different experimental methods and heating menstruum (Waterman, 1982; Sorqvist, 1989; Blankenship and Craven, 1982; Doyle and Roman, 1982).

\section{Appendix B.2Fixed-temperature, varying pH experiments}

Humphrey and Lanning had taken scald water samples at the end of a working day from a scald tank and used these samples as heating menstruum to experimentally determine $C$. jejuni D-values at $52{ }^{\circ} \mathrm{C}$ (Humphrey and Lanning, 1987). The scald water samples contained $13 \mathrm{mg} / \mathrm{ml}$ total solids and $6.2 \mathrm{mg} / \mathrm{ml}$ proteins. To quantify the impact of $\mathrm{pH}$ on $\mathrm{C}$. jejuni kill rate, varying levels of sodium hydroxide $(\mathrm{NaOH})$ and hydrogen chloride $(\mathrm{HCl})$ were used to control the $\mathrm{pH}$ of the scald water samples (Humphrey and Lanning, 1987). In particular, Humphrey and Lanning find D-values at constant temperature $52^{\circ} \mathrm{C}$ and $\mathrm{pH}$ values of $4,6,7,8,9$, and 10 to be $0.4 \pm 0.02 \mathrm{~min}, 8.72 \pm 0.12 \mathrm{~min}$,

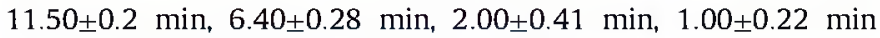
respectively (Humphrey and Lanning, 1987).

\section{Appendix B.3Parameter estimation for model (1)}

Recall the form of the inactivation model (1) is given by: $D_{w_{i}}(p H, T)=D(p H)\left[D_{i}(T)\right]$, where $D(p H)=\hat{a} e^{-((p H-b / c))^{2}}$ and $D_{l}(T)=a_{i} e^{b_{i}\left(T-T_{\text {ref }}\right)}$. The following provides details concerning parameter estimates, using MATLAB's 'cftool' for the model forms with respect to $\mathrm{pH}$ and temperature.

To estimate parameters for $D(p H)$, the fixed-temperature $C$. jejuni D-value data from (Humphrey and Lanning, 1987) is used to construct a $95 \%$ confidence interval (CI). For each pH sample mean ( $x$ ), D-values are reported with their associated standard error (Humphrey and Lanning, 1987). We obtain the upper bound on the $95 \% \mathrm{CI}$ by fitting the points $\bar{x}+1.96 \cdot \mathrm{SE}$ to a Gaussian $D_{U}(p H)$. Data fitting yields co-

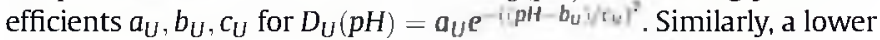
95\% $\mathrm{CI}$ bound is obtained by fitting $\bar{x}-1.96 \cdot \mathrm{SE}$ to $D_{L}(\mathrm{pH})=a_{L} e^{-\left\langle\left(p H-b_{L}\right) / c_{L}\right)^{2}}$ (see Fig. 1B). The data fitting results, along with the respective $95 \% \mathrm{Cl}$ given as an open interval, are $a_{U}=11.62(9.60,13.63), b_{U}=6.86(6.57,7.15), c_{U}=1.72(1.28$. $2.16)$ and $a_{L}=11.3(10.5,12.1), b_{L}=6.80(6.70,6.89), c_{L}=1.49$ $(1.33,1.64)$.

For $D_{i}(T)$, we use an exponential thermal inactivation model as outlined in (Bazin and Prosser, 1988) with data fitting to the D-value vs. temperature data. The D-values for 17 strains of $C$. jejuni (coming from (Al Sakkaf and Jones, 2012; Doyle and Roman, 1982; Sorqvist, 1989; Blankenship and Craven, 1982; Waterman, 1982; Nguyen et al., 2006)) are each fit to exponential functions $D_{i}(T)=a_{i} e^{b_{i}\left(T-T_{\text {ref }}\right)}$, where $T_{\text {ref }}=52^{\circ} \mathrm{C}$. Notice that since the D-value vs. $\mathrm{pH}$ experiments (Humphrey and Lanning, 1987), used to determine $D(p H)$, take place in actual scald water at $52^{\circ} \mathrm{C}$ with high concentrations of organic material and proteins, we set $T_{\text {ref }}=52^{\circ} \mathrm{C}$. In addition, we only retain the decay information for each strain given by $b_{i}$ and reset the estimated $a_{\imath}$ to be 1 . See Table B.4 for fitting results (note that we only report the $b$ values and respective $C I$ relative to each strain). The reasoning here is that we rescale the $D_{i}(T)$ equation so that $D_{L}(p H) \leq D_{W_{i}}\left(p H, T_{\text {ref }}\right) \leq D_{U}(p H)$. Note that, by setting $a_{i}=1$ and $T_{\text {ref }}=52^{\circ} \mathrm{C}$, we impose the condition that model (1) determined D-values agree with the cross-section illustrated in Fig. 1B. In effect, this allows us to have an inactivation model in the water that is linked as close as possible to data from industrial scalding.

Table B.4

Results of parameter estimation for decay rates of $D(T)$ relative to $C$. jejuni strain

\begin{tabular}{llll}
\hline Strain & $\mathrm{b}$ & $95 \% \mathrm{Cl}$ & Reference \\
\hline AR6 & -0.38 & $(-0.42,-0.35)$ & (Nguyen et al., 2006) \\
L51 & -0.43 & $(-0.56,-0.29)$ & \\
CF3 & -0.42 & $(-0.43,-0.39)$ & (Doyle and Roman, 1982) \\
CF6 & -0.26 & $(-0.36,-0.16)$ & \\
CF8 & -0.32 & $(-0.50,-0.15)$ & \\
CF12 & -0.48 & $(-0.71,-0.25)$ & \\
CF16 & -0.39 & $(-0.48,-0.30)$ & \\
5388 & -0.61 & $(-0.99,-0.23)$ & (Waterman, 1982) \\
21033 & -0.92 & $(-2.22,0.38)$ & \\
16000 & -0.57 & $(-1.32,0.19)$ & \\
16509 & -0.61 & $(-1.36,0.13)$ & \\
17259 & -0.62 & $(-2.85,1.61)$ & \\
24791 & -0.38 & $(-2.01,1.24)$ & (Sorqvist, 1989) \\
1503 & -0.54 & $(-1.37,0.28)$ & (Al Sakkaf and Jones, 2012) \\
ST45 & -0.66 & $(-0.73,-0.59)$ & \\
ST190 & -0.54 & $(-0.58,-0.49)$ & \\
ST474 & -0.56 & $(-0.82,-0.30)$ & \\
\hline
\end{tabular}

To account for all experimental variation in temperature decay, we allow $D_{w}(p H, T)$ to vary between $D_{w_{i}}$ for all $C$. jejuni strains $i$. Naturally, there are lower and upper bounding $D_{w_{i}}$ for which the lowest and highest D-values are seen. By allowing $D_{w}$ to vary between these lower and upper bounds, we retrieve our inactivation model which addresses items 1), 2), and 3) proposed in Section 2.2. Among the 17 C. jejuni strains, we find the steepest temperature decay in Waterman's strain $21033\left(b_{21033}=-0.92\right)$. On the other hand, the $C$. jejuni strain with the most mild temperature decay is strain CF6 found in $b_{C F 6}=-0.26$ Doyle and Roman (1982). Finally, we obtain the inactivation model

$\begin{cases}D_{L_{C F 6}} \leq D_{W} \leq D_{U_{21033}} & T \leq 52^{*} C \\ D_{L_{21033}} \leq D_{W} \leq D_{U_{\text {GF }}} & T \geq 52^{\circ} \mathrm{C} .\end{cases}$

\section{Appendix C. Generating solutions to model (3) as illustrated} in Fig. 3

We outline the procedure for producing a single curve in Fig. 3. The idea is to take random samples from the provided ranges in Table 1 at $54.15^{\circ} \mathrm{C}$ to completely determine scald model (3) parameters. In other words, we aim to provide single values for $k_{c w}, I_{c}$, and $I_{w}$. Sampling from the uniform distribution $U(0,1)$, we may then generate corresponding parameter values. For example, shed rate $k_{c w}$ lies between 0.31 and $1.551 / \mathrm{min}$, we generate a value in this interval using the following transformation $k_{c w}=0.31+r_{1}(1.55-0.31)$ where $r_{1}$ is a random sample from $U(0,1)$. In the case of Figure AppendixC we generate $r_{1}=0.65$ and as a result $k_{c w}=1.111 / \mathrm{min}$. Similarly, for the carcass inactivation rate $I_{c}$ and the water inactivation rate $I_{w}$, sampling from $U(0,1)$ to obtain $r_{2}=0.39$ and $r_{3}=0.75$, then plugging the respective values into $I_{C}=0.74+r_{2}(1.98-0.74) \quad$ and $I_{w}=0.54+r_{3}(2.82-0.54)$, we determine $I_{c}=1.541 / \mathrm{min}$ and $I_{W}=2.01 \mathrm{1} / \mathrm{min}$. In general, a sample for parameter $p$ which varies from $p_{\min }$ to $p_{\max }$ may be generated by computing $p=p_{\min }+U(0,1)\left(p_{\max }-p_{\min }\right)$. 
The curves in Figure AppendixC are produced using MATLAB's ODE45 to solve the scald model (3) with the values for $k_{c w} . I_{c}$, and $I_{w}$ found above as well as fixed values found in Table 1 . The method for generating $n=1000$ curves in Fig. 3 is similar.

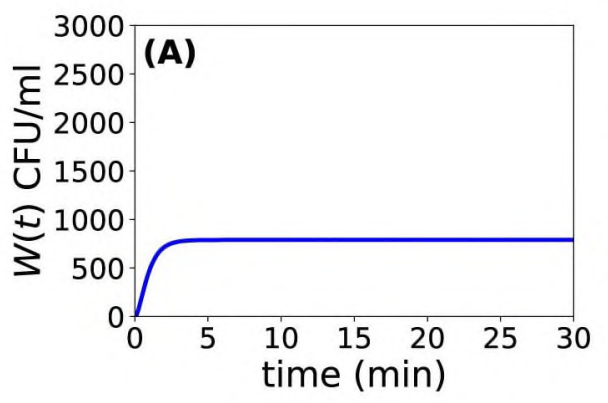

Time dynamics of $W$

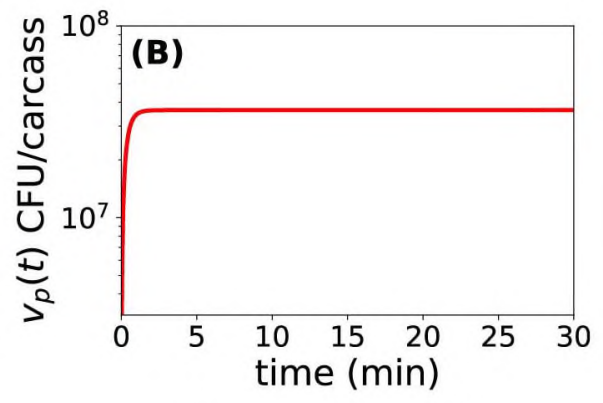

Time dynamics of $v_{p}$

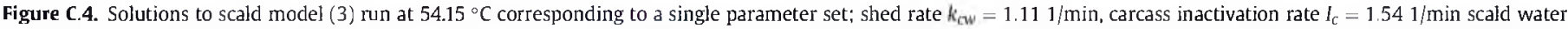

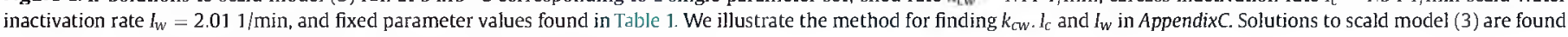
numerically using MATLAB's ODE45 using initial conditions $v_{p}(0)=0, W(0)=0$.

\section{References}

Al Sakkaf, Ali, Jones, Geoff, 2012. Thermal inactivation of Campylobacter jejuni in brotl. J. Food Prot. 75 (6), 1029-1035.

Bazin, M.J., Prosser, J., 1988. Physiological Models in Microbiology li, Crc Series in Mathematical Models in Microbiology.

Bennett, P., 2008. Compliance Guideline for Controlling Salmonella and Campylobacter in Poultry.

Berrang, M.E., Windham, W.R., Meinersmann, R.I., 2011. Campylobacter, Salmonella, and Escherichia coli on broiler carcasses subjected to a high ph scald and low ph postpick chlorine dip. Poult. Sci. 90 (4), 896-900.

Blankenship, L.C., Craven, S.E., 1982. Campylobacter jejuni survival in chicken meat as a function of temperature. Appl. Environ. Microbiol. 44 (1), 88-92.

Cason, J.A., Whittemore, A.D., Shackelford, A.D., 1999. Aerobic bacteria and solids in a three-tank, two-pass, counterflow scalder: Poult. Sci. 78 (1), 144-147.

Cerf, O., Davey, K.R., Sadoudi, A.K., 1996. Thermal inactivation of bacteria - a new predictive model for the combined effect of three environmental factors: temperature, ph, and water activity. Food Res. Int. 29, 210-226.

Doyle, Michael P., Roman, Debra J., 1982. Prevalence and survival of Campylobacter jejuni in unpasteurized milk. Appl. Environ. Microbiol. 44 (5), 1154-1158.

FAO/WHO, 2009. Risk Assessment of Campylobacter Spp. In Broiler Chickens: Technical Report.

Gaillard, S., Leguerinel, I., Mafart, P., 1998. Model for combined effects of temperature, ph and water activity on thermal inactivation of bacillus cereus spores. J. Food Sci. 63, 887-889.

Humphrey, T.J., Lanning, D.G., 1987. Salmonella and Campylobacter contamination of broiler chicken carcasses and scald tank water: the influence of water ph. I. App. Bacteriol. 63 (1), $21-25$.

Lillard, H.S., Blankenship, L.C., Dickens, J.A., Craven, S.E., Shackelford, A.D., 1987. Effect of acetic acid on the microbiological quality of scalded picked and unpicked broiler carcasses. J. Food Prot. 50 (2), 112-114.

Marino, Simeone, Hogue, lan B., Ray, Christian J., Kirschner, Denise E., 2008. A methodology for performing global uncertainty and sensitivity analysis in systems biology. I. Theor. Biol. 254 (1), 178-196.

McCarthy, Zachary, Smith, Ben, Fazil, Aamir, Wu, Jianhong, Ryan, Shawn D., Munther, Daniel, 2017. Individual based modeling and analysis of pathogen levels in poultry chilling process. Math. Biosci. (294), 172-180.

Mckee, S.R., Townsend, J.C., Bilgili, S.F., 2008. Use of a scald additive to reduce levels of Salmonella Typhimurium during poultry processing. Poult. Sci. 87 (8), 1672-1677.

Moran, Lynn, Scates, P.A.M., Madden, Robert H., 2009. Prevalence of Campylobacter spp. in raw retail poultry on sale in northern Ireland. J. Food Prot. 72 (9), 1830-1835.

Mulder, R.W.A.W., Dorresteijn, L.W.J., Van Der Broek, J., 1978. Cross-contamination during the scalding and plucking of broilers. Br. Poult. Sci. 19 (1), 61-70.

Munther, Daniel, Sun, Xiaodan, Xiao, Yanni, Tang, Sanyi, Shimozako, Helio, Wu, Jianhong, Smith, Ben A., Fazil, Aamir, 2016. Modeling cross-contamination during poultry processing: dynamics in the chiller tank. Food Control 59, $271-281$.

Nguyen, Hong TT., Corry, Janet EL., Miles, Christopher A., 2006. Heat resistance and mechanism of heat inactivation in thermophilic campylobacters. Appl. Environ. Microbiol. 72 (1), 908-913.

Okrend, Anita J, Johnston, Ralph W, Moran, Alice B, July 1986. Effect of acetic acid on the death rates at $52 \mathrm{c}$ of Salmonella newport, Salmonella typhimurium and Campylobacter jejuni in poultry scald water. I. Food Prot. 49 (7), 500-503.

Olson, Christine K., Ethelberg, Steen, Pelt, Wilfrid van, Tauxe, Robert V., 2008. Epidemiology of Campylobacter jejuni infections in industrialized nations. In: Campylobacter, third ed. American Society of Microbiology, pp. 163-189.

Osiriphun, Sukhuntha, Tuitemwong Pravate, Koetsinchai, Woranut, Tuitemwong, Kooranaee, Erickson, Larry E., 2012. Model of inactivation of Campylobacter jejuni in poultry scalding. J. Food Eng. 110 (1), 38-43.

Osiriphun, Sukhuntha, Koetsinchai, Woranut, Tuitemwong, Kooranaee, Erickson, Larry E., Tuitemwong, Pravate, 2015. Inactivation and crosscontamination models of Campylobacter jejuni in scalding of chicken process. URL https://www.researchgate.net/profile/Pravate Tuittemwong/publication/ 268376310 INACTIVATION AND CROSS-CONTAMINATION MODELS OF CAMPYLOBACTER_JEJUNI_IN_SCALDING_OF_CHICKEN_PROCESS/links/ $55431 \mathrm{c} 130 \mathrm{cf} 234 \mathrm{bdb} 21 \mathrm{a} 312 \mathrm{~d}$. pdf. .

Sorqvist, S., 1989. Heat resistance of Campylobacter and Yersinia strains by three methods. J. Appl. Bacteriol. 67 (5), 543-549.

Sukted, Nion, Tuitemwong, Pravate, Tuitemwong, Kooranee, Poonlapdecha, Wanwisa, Erickson, Larry E., 2017. Inactivation of campylobacter during immersion chilling of chicken carcasses. J. Food Eng. 202, 25-33.

Suzuki, Hodaka, Yamamoto, Shigeki, 2009. Campylobacter contamination in retail poultry meats and by-products in Japan: a literature survey. Food Control 20 (6) 531-537.

Food Safety US Department of Agriculture and Inspection Service, 2015. Changes to the salmonella and campylobacter verification testing program: proposed performance standards for salmonella and campylobacter in not-ready-to-eat comminuted chicken and Turkey products and raw chicken parts and related agency verification procedures and other changes to agency sampling. Fed. Regist. 80, 3940-3950.

Waterman, Sally C., 1982. The heat-sensitivity of Campylobacter jejuni in milk. J. Hyg-Cambridge 88 (03), 529-533.

Yang, Hong, Li, Yanbin, Johnson, Michael G., 2001. Survival and death of Salmonella Typhimurium and Campylobacter jejuni in processing water and on chicken skin during poultry scalding and chilling. J. Food Prot. 64 (6), 770-776. 